\title{
Sildenafil: a definitive NO in COPD
}

\author{
Anton Vonk-Noordegraaf and Bart G. Boerrigter \\ Affiliations: Dept of Pulmonology, VU University Medical Center/Institute for Cardiovascular Research, \\ Amsterdam, The Netherlands.
}

Correspondence: A. Vonk-Noordegraaf, Dept of Pulmonology, VU University Medical Center, Boelelaan 1117, 1007 MB Amsterdam, The Netherlands. E-mail: a.vonkavumc.nl

0 @ERSpublications A decade of studies indicate there is no place for sildenafil in COPD http://ow.ly/nFHrI

Several studies have shown that chronic obstructive pulmonary disease (COPD) patients have a low stroke volume at rest and an impaired stroke volume response during exercise $[1,2]$. As a consequence, oxygen delivery to the tissues is impaired. Since oxygen delivery is critical for maintenance and growth of muscles, the systemic effects of COPD might, in part, be attributed to the lowered stroke volume. Therefore, restoring the stroke volume response would not only improve oxygen delivery capacity, but may also have beneficial effects at the muscle level. Improving muscle strength may, in turn, enhance exercise tolerance by reducing negative feedback from lower limb sensory muscle afferents and by reducing ventilatory responses and dyspnoea during exercise [3].

Since increased right ventricular afterload is considered the most likely explanation for the impaired stroke volume response, reducing pulmonary artery pressure is the key to restore stroke volume. Although pulmonary hypertension is present in $50 \%$ of the patients with severe COPD, pulmonary hypertension is usually mild-to-moderate [4]. However, exercise will induce a steep increase in pulmonary artery pressure in these patients $[5,6]$. Several factors may contribute to this exercise-related increase in pulmonary artery pressure, and active pulmonary vasoconstriction in the pulmonary areas that are non-well perfused and hypoxaemia are considered crucial. Abolishing hypoxic pulmonary vasoconstriction could increase exercise capacity. One way to do this is to use the phosphodiesterase type 5 (PDE5) inhibitor sildenafil. Inhibition of PDE5 delays the degradation of cyclic guanosine monophosphate, thereby enhancing the vasodilator activity of nitric oxide in the pulmonary vessels. A proof of concept study was performed by GHOFRANI et al. [7], in which healthy subjects were exposed to hypoxia at high altitude. In a crossover design this group showed that pulmonary artery pressure can be reduced by oral intake of sildenafil and that this decrease in pressure is accompanied by an increase in exercise capacity. The beneficial acute effect of sildenafil on pulmonary artery pressure during submaximal exercise in COPD patients was confirmed by HOLVERDA et al. [8]. It is of interest that this study showed no benefit from the reduction in pulmonary artery pressure on stroke volume, cardiac output or exercise capacity. Although some benefit was reported in selected patients, RIETEMA et al. [9] could not find beneficial effects of the use of sildenafil on maximal exercise capacity or on noninvasive parameters of right ventricular function during a 3-month study in COPD patients. A limitation of this study was its uncontrolled design and the absence of patients with severe pulmonary hypertension (mean pulmonary artery pressure $22 \pm 9 \mathrm{mmHg}$ ). In a previous study, BLANCO et al. [10] showed that sildenafil can cause hypoxaemia under resting conditions, most likely due to the release of hypoxic pulmonary vasoconstriction, raising a word of caution for the use of sildenafil in COPD. Despite this side-effect of sildenafil in COPD and the negative study [9], the question still remained whether sildenafil was tested in an adequate way, since maximal exercise capacity is limited by ventilation and not by circulation in the majority of the patients [11] and, therefore, maximal exercise testing might be an inadequate method to test the benefit in COPD.

Received: June 252013 | Accepted after revision: Aug 032013

Conflict of interest: Disclosures can be found alongside the online version of this article at www.erj.ersjournals.com

Copyright (CERS 2013 
To address this question BLANCO et al. [12] performed another double-blind, randomised, controlled trial, published in this issue of the European Respiratory Journal, taking endurance time at submaximal exercise after a period of rehabilitation as their primary end-point. Indeed, if stroke volume response at exercise is improved in COPD one would expect beneficial effects of sildenafil on muscle strength, as well in endurance time, at submaximal exercise level. Endurance testing has been shown to be a sensitive end-point in COPD [13]. Pulmonary artery pressure was estimated by echocardiography in the majority of patients. Based on the mean value of maximum tricuspid regurgitation velocity $\left(3.06 \pm 0.28 \mathrm{~m} \cdot \mathrm{s}^{-1}\right)$ it can be concluded that pulmonary artery pressure was, on average, slightly increased in this study population.

Respiratory rehabilitation improved exercise tolerance in this cohort of patients with COPD and pulmonary hypertension irrespective of whether they received sildenafil or placebo. Although we do not know whether pulmonary artery pressure was adequately lowered during exercise, this study, yet again, showed no effect of sildenafil on the different measures of exercise capacity, which were the primary and secondary end-points [12]. The fact that exercise tolerance can be improved by rehabilitation, irrespective of pulmonary vasodilator therapy, indicates once again that exercise capacity, and also the potential to improve peripheral muscle strength during rehabilitation, in this group of patients is not determined by the presence of mild pulmonary hypertension.

Is this the end of story for sildenafil in COPD? On top of previous studies showing no improvement in exercise capacity $[8,9]$ or worsening of gas exchange [10] in COPD patients without or with mild pulmonary hypertension, this study shows that sildenafil does not improve outcomes of respiratory rehabilitation in COPD patients with moderate pulmonary hypertension [12]. Pulmonary vasodilator treatment of COPD patients with severe pulmonary hypertension (mean pulmonary artery pressure $>35-40 \mathrm{mmHg}$ ) [14] and circulatory exercise impairment remains unstudied. The low prevalence of this condition might explain why these studies have not been performed to date [4, 14]. With the exception of this group it is safe to conclude that after a decade of studies there is no place for sildenafil in COPD.

\section{References}

1 Light RW, Mintz HM, Linden GS, et al. Hemodynamics of patients with severe chronic obstructive pulmonary disease during progressive upright exercise. Am Rev Respir Dis 1984; 130: 391-395.

Stewart RI, Lewis CM. Cardiac output during exercise in patients with COPD. Chest 1986; 89: 199-205.

Gagnon P, Bussières JS, Ribeiro F, et al. Influences of spinal anesthesia on exercise tolerance in patients with chronic obstructive pulmonary disease. Am J Respir Crit Care Med 2012; 186: 606-615.

4 Chaouat A, Bugnet AS, Kadaoui N, et al. Severe pulmonary hypertension and chronic obstructive pulmonary disease. Am J Respir Crit Care Med 2005; 172: 189-194.

5 Burrows B, Kettel LJ, Niden AH, et al. Patterns of cardiovascular dysfunction in chronic obstructive lung disease. N Engl J Med 1972; 286: 912-918.

6 Hilde JM, Skjørten I, Hansteen V, et al. Haemodynamic responses to exercise in patients with COPD. Eur Respir J 2013; 41: 1031-1041.

7 Ghofrani HA, Reichenberger F, Kohstall MG, et al. Sildenafil increased exercise capacity during hypoxia at low altitudes and at Mount Everest base camp: a randomized, double-blind, placebo-controlled crossover trial. Ann Intern Med 2004; 141: 169-177.

8 Holverda S, Rietema H, Bogaard HJ, et al. Acute effects of sildenafil on exercise pulmonary hemodynamics and capacity in patients with COPD. Pulm Pharmacol Ther 2008; 21: 558-564.

9 Rietema H, Holverda S, Bogaard HJ, et al. Sildenafil treatment in COPD does not affect stroke volume or exercise capacity. Eur Respir J 2008; 31: 759-764.

10 Blanco I, Gimeno E, Munoz PA, et al. Hemodynamic and gas exchange effects of sildenafil in patients with chronic obstructive pulmonary disease and pulmonary hypertension. Am J Respir Crit Care Med 2010; 181: 270-278.

11 Boerrigter BG, Bogaard HJ, Trip P, et al. Ventilatory and cardiocirculatory exercise profiles in COPD: the role of pulmonary hypertension. Chest 2012; 142: 1166-1174.

12 Blanco I, Santos S, Gea J, et al. Sildenafil to improve respiratory rehabilitation outcomes in COPD: a controlled trial. Eur Respir J 2013; 42: 982-992.

13 Oga T, Nishimura K, Tsukino M, et al. The effects of oxitropium bromide on exercise performance in patients with stable chronic obstructive pulmonary disease. A comparison of three different exercise tests. Am J Respir Crit Care Med 2000; 161: 1897-1901.

14 Hurdman J, Condliffe R, Elliot CA, et al. Pulmonary hypertension in COPD: results from the ASPIRE registry. Eur Respir J 2013; 41: 1292-1301. 